\title{
BNCC e as práticas epistêmicas e científicas nos anos finais do ensino fundamental
}

\author{
$B N C C$ and epistemic and scientific practices in the final years of \\ fundamental education
}

\begin{abstract}
Anazia Aparecida Reis (naniapreis@ hotmail.com)
(Mestranda bolsista Fapes do Programa de Pós-Graduação Mestrado Profissional - PPGMPE; Grupo de pesquisa Formação de professores, linguagem e cultura em educação em Ciências do Laboratório de Educação em Ciências - LabEC; Universidade Federal do Espírito Santo - UFES)
\end{abstract}

Elaine Cristina Apolinário de Azevedo (elaine.apolinario@gmail.com) (Grupo de pesquisa Formação de professores, linguagem e cultura em educação em Ciências do Laboratório de Educação em Ciências - LabEC; Universidade Federal do Espírito Santo - UFES)

Junia Freguglia (junia.freguglia@gmail.com)

(Docente do Programa de Pós-Graduação Mestrado Profissional - PPGMPE; Grupo de pesquisa Formação de professores, linguagem e cultura em educação em Ciências do Laboratório de Educação em Ciências - LabEC; Universidade Federal do Espírito Santo - UFES)

Lidiane dos Santos Scarabelli Ribeiro (lidiscarabelli@gmail.com)

(Mestranda do Programa de Pós-Graduação Mestrado Profissional; Grupo de pesquisa Formação de professores, linguagem e cultura em educação em Ciências do Laboratório de Educação em Ciências LabEC; Universidade Federal do Espírito Santo - UFES)

Resumo: A Base Nacional Comum Curricular (BNCC) orienta o ensino de Ciências na perspectiva do Letramento Científico. Em que pese o debate em torno da BNCC e da definição do termo letramento para a educação científica, este trabalho visa contribuir para a pesquisa e para a prática no ensino de Ciências, apresentando a identificação e análise das práticas científicas e epistêmicas associadas às habilidades propostas pela BNCC para os anos finais do ensino fundamental na área de Ciências da Natureza, tomando como referência pesquisa semelhante realizada por Sasseron sobre os anos iniciais. Assim, constatamos que, em todo o ensino fundamental, a área de Ciências da Natureza da BNCC apresenta maior associação a práticas científicas do que a práticas epistêmicas e que existe um número elevado de habilidades sem associação a práticas epistêmicas, bem como uma elevada quantidade de habilidades que não apresentam práticas epistêmicas e práticas científicas em concomitância. Além disso, há alta incidência de práticas comuns ao ensino tradicionalmente marcado pela passividade dos estudantes e por atividades de reprodução, em detrimento de outras que avançam no sentido da inserção dos estudantes na cultura científica, indicando incoerências e contradições importantes de serem observadas no planejamento de estratégias de ensino e aprendizagem.

Palavras-chave: BNCC; alfabetização científica; práticas científicas e epistêmicas; ensino de ciências. 
Abstract: The National Common Curricular Base (BNCC) guides the teaching of Science from the perspective of Scientific Literacy. Despite the debate around BNCC and the definition of the term literacy for science education, this work aims to contribute to research and practice in science education, presenting the identification and analysis of scientific and epistemic practices associated with the proposed skills by BNCC for the final years of elementary school in the area of Natural Sciences, taking as a reference similar research carried out by Sasseron on the early years. Thus, we found that throughout the elementary school, the area of Natural Sciences at BNCC has a greater association with scientific practices than with epistemic practices and that there is a high number of skills without association with epistemic practices, as well as a high amount of skills that do not present epistemic practices and scientific practices concurrently. In addition, there is a high incidence of practices common to teaching traditionally marked by the passivity of students and by reproduction activities, to the detriment of others that advance towards the insertion of students in scientific culture, indicating important inconsistencies and contradictions to be observed in planning teaching and learning strategies.

Keywords: BNCC; scientific literacy; scientific and epistemic practices; science education

\section{INTRODUÇÃO}

O presente trabalho é derivado de uma investigação de mestrado do Programa de Pós-graduação Mestrado Profissional em Educação da Universidade Federal do Espírito Santo (PPGMPE), em andamento, com a colaboração do grupo de pesquisa Formação de professores, linguagem e cultura em educação em Ciências (GPFEC). O que se apresenta aqui é a identificação e análise das práticas epistêmicas e científicas contidas nas habilidades da BNCC para o $6^{\circ}, 7^{\circ}, 8^{\circ}$ e $9^{\circ}$ anos do ensino fundamental apoiadas na delimitação dessas práticas apresentada por Sasseron (2018) e em sua análise do mesmo documento para os anos iniciais do ensino fundamental.

Reconhecemos o debate em torno da implementação de uma base comum curricular e, por isso, consideramos importante analisar aproximações e distanciamentos entre o documento oficial e estudos realizados nas áreas que o compõem. Essa deve ser a contribuição desta pesquisa para o ensino na área de Ciências da Natureza.

\section{Base Nacional Comum Curricular}

A Base Nacional Comum Curricular (BNCC) é um documento do Ministério da Educação (MEC) cuja elaboração contou com a participação do Conselho Nacional de Secretários de Educação (CONSED) e da União Nacional dos Dirigentes Municipais de 
Educação (UNDIME), sendo sua versão final, para o ensino fundamental, publicada em 2017.

Concordamos com Macedo (2014, p.1549) quando considera que a BNCC representa "a construção de uma nova arquitetura de regulação e de que, nela, os sentidos hegemonizados para educação de qualidade estão relacionados à possibilidade de controle do que será ensinado e aprendido". Entretanto, também pactuamos com Silva (2019, p. 15), ao observar a contradição da proposta para a área de Ciências da Natureza, no documento:

[...] a área de ciências da natureza assume uma perspectiva de educação científica problematizadora e emancipatória dos sujeitos (...) por articular como eixos estruturantes das proposições curriculares a alfabetização científica (entendida por nós como a capacidade de compreender e interpretar o mundo (natural, social e tecnológico), mas também de transformá-lo com base nos aportes teóricos e processuais das ciências.); abordagem investigativa (que busca promover o protagonismo dos estudantes na aprendizagem e aplicação de processos, práticas sociais típicas da cultura escolar) e a contextualização (Contextualização histórica, cultural, social, tecnológica, cotidiana, CTS da ciência) (SILVA, 2019, p. 15).

As orientações para área das Ciências da Natureza estão especificadas no item 4.3 do documento, e apontam, na realidade, o letramento científico como foco para a educação científica (MEC, 2017). Todavia, os termos - letramento e alfabetização convergem, pela leitura do documento, para o sentido que apresentamos anteriormente, a partir das considerações de Silva (2019).

O termo "letramento científico" deriva-se da tradução da língua inglesa "Scientific Literacy”. Sasseron e Carvalho (2011) discorrem sobre a dificuldade da tradução do termo para a língua portuguesa, uma vez que ele ganha diferença semântica quando oriundo da língua espanhola ou francesa, sendo traduzido como alfabetização científica (AC). Ademais, pode-se encontrar o termo "enculturação científica" traduzido do inglês e francês para outros idiomas antes de ser traduzido para o português. Dessa forma temos, em língua portuguesa, diferentes termos, como Alfabetização Científica, Letramento Científico e Enculturação Científica para denominarmos um ensino de Ciências que, apesar de terem limites diferentes, convergem para um ensino que tem como objetivo "a construção de benefícios práticos para as pessoas, a sociedade e o meio-ambiente" (SASSERON, CARVALHO, 2011, p.60). 
O termo assumido neste trabalho será "alfabetização científica", o mesmo assumido por Sasseron e Carvalho (2011) e que, nas palavras das autoras, remete a:

\begin{abstract}
Um ensino que permita aos alunos interagir com uma nova cultura, com uma nova forma de ver o mundo e seus acontecimentos, podendo modificá-los e a si próprio através da prática consciente propiciada por sua interação cerceada de saberes de noções e conhecimentos científicos, bem como das habilidades associadas ao fazer científico (SASSERON, CARVALHO, 2011, p. 61).
\end{abstract}

Há ainda, na BNCC, orientações para ações investigativas para o ensino de Ciências. Podem-se entender essas ações investigativas como a promoção da abordagem do ensino por investigação, sendo ele defendido como uma abordagem didática apropriada para o desenvolvimento da alfabetização científica em aulas de Ciências. Nesse sentido, Sasseron (2018) defende a prática científica no ensino, que tem como principais elementos a autonomia das/dos estudantes e um aprendizado além da conceituação, estando associada a um ensino que introduza as/os estudantes na cultura científica, à construção da educação científica focada na relação entre as práticas cotidianas e as práticas de ensino e a uma aprendizagem que intencione a mudanças de práticas sociais (SASSERON, 2018). Para tanto, Sasseron e Carvalho (2011) propõem três eixos estruturantes da alfabetização científica para os quais as atividades de ensino de ciências devem ser direcionadas: (i) a compreensão básica de termos, conhecimentos e conceitos científicos fundamentais; (ii) a compreensão da natureza das ciências e dos fatores éticos e políticos que circundam sua prática; e (iii) o entendimento das relações existentes entre ciência, tecnologia, sociedade e meio-ambiente.

A BNCC ainda traz os principais objetivos para a área das Ciências da Natureza, assim como competências específicas que abrangem todo o ensino fundamental, sem distinção entre anos iniciais e anos finais. O documento também apresenta, para a área, três unidades temáticas: Matéria e energia, Vida e evolução e Terra e Universo. Essas correspondem a objetos do conhecimento e seus objetivos, apresentados como habilidades.

As competências presentes na BNCC são apresentadas no quadro 1 e são compreendidas como "os conhecimentos, as habilidades, as atitudes e os valores para atuação na vida cotidiana, exercício da cidadania e inserção no mundo do trabalho" (SASSERON, 2018, p.1069). 
Quadro 1 - competências específicas da área de Ciências da Natureza da BNCC

1. Compreender as Ciências da Natureza como empreendimento humano, e o conhecimento científico como provisório, cultural e histórico.

2. Compreender conceitos fundamentais e estruturas explicativas das Ciências da Natureza, bem como dominar processos, práticas e procedimentos da investigação científica, de modo a sentir segurança no debate de questões científicas, tecnológicas, socioambientais e do mundo do trabalho, continuar aprendendo e colaborar para a construção de uma sociedade justa, democrática e inclusiva.

3. Analisar, compreender e explicar características, fenômenos e processos relativos ao mundo natural, social e tecnológico (incluindo o digital), como também as relações que se estabelecem entre eles, exercitando a curiosidade para fazer perguntas, buscar respostas e criar soluções (inclusive tecnológicas) com base nos conhecimentos das Ciências da Natureza.

4. Avaliar aplicações e implicações políticas, socioambientais e culturais da ciência e de suas tecnologias para propor alternativas aos desafios do mundo contemporâneo, incluindo aqueles relativos ao mundo do trabalho.

5. Construir argumentos com base em dados, evidências e informações confiáveis e negociar e defender ideias e pontos de vista que promovam a consciência socioambiental e o respeito a si próprio e ao outro, acolhendo e valorizando a diversidade de indivíduos e de grupos sociais, sem preconceitos de qualquer natureza.

6. Utilizar diferentes linguagens e tecnologias digitais de informação e comunicação para se comunicar, acessar e disseminar informações, produzir conhecimentos e resolver problemas das Ciências da Natureza de forma crítica, significativa, reflexiva e ética.

7. Conhecer, apreciar e cuidar de si, do seu corpo e bem-estar, compreendendo-se na diversidade humana, fazendo-se respeitar e respeitando o outro, recorrendo aos conhecimentos das Ciências da Natureza e às suas tecnologias.

8. Agir pessoal e coletivamente com respeito, autonomia, responsabilidade, flexibilidade, resiliência e determinação, recorrendo aos conhecimentos das Ciências da Natureza para tomar decisões frente a questões científico-tecnológicas e socioambientais e a respeito da saúde individual e coletiva, com base em princípios éticos, democráticos, sustentáveis e solidários.

Fonte: BNCC (MEC, 2017, p.324).

Ao interpretar as competências apresentadas, podemos afirmar que o documento tem por objetivo promover um ensino em que a ciência seja percebida como uma produção social, histórica e cultural; aborda questões científicas, tecnológicas, sociais e ambientais, além de desenvolver práticas próprias do fazer científico. Portanto, a BNCC expressa também, em suas competências, a promoção de um ensino de Ciências que vai ao encontro da alfabetização científica delineada por Sasseron e Carvalho (2011), que compreendem que a produção de conhecimento por cientistas é histórica, cultural e social e que se realiza por meio de práticas próprias da comunidade científica.

\section{Práticas epistêmicas e científicas}

Como visto anteriormente, tanto no objetivo da alfabetização científica aqui assumido, quanto nas competências da BNCC, o ensino de Ciências deve promover o 
Edição Especial: I SSAPEC - Simpósio Sul-Americano de Pesquisa em Ensino de Ciências

ISSN: 2595- $4520 \quad$ Vol. 4, n. 3. 2021

fazer próprio da ciência, de forma a inserir as/os estudantes nos modos de produzir e comunicar conhecimento científico.

Na produção de conhecimento sobre o ensino de Ciências, essa prática tem se configurado sob duas formas, conforme Sasseron (2018) explora em seus estudos: as práticas epistêmicas e as práticas científicas. A autora ressalta a possibilidade de distingui-las teoricamente, mas considera que seu caráter prático é concomitante, colaborativo e mútuo. Sendo assim, as práticas científicas são aquelas de produção do conhecimento dos cientistas e das cientistas.

Duchl (2008) defende que a aprendizagem no ensino de ciências ocorra através da participação das/dos estudantes nessas práticas, uma vez que estudos sobre aprendizagem têm apontado que a inserção das/dos estudantes em práticas semelhantes a das/dos cientistas, as quais intenciona-se ensinar, apresentam aprendizados mais profundos, considerando a dinâmica indissociável entre contexto e conteúdo. Logo, saber o que é preciso para fazer ciência não é o suficiente para aprender o fazer científico.

Em um contexto educacional, podemos compreender as práticas científicas como o desenvolvimento da compreensão do trabalho dos/das cientistas pelas/pelos estudantes (OSBORNE, 2011 apud JIMÉNEZ-ALEIXANDRE E CRUJEIRAS, 2018), permitindo ultrapassar um ensino-aprendizagem reproducionista, haja vista que o trabalho dos/das cientistas é produzir conhecimento e este seria também o objetivo da educação científica escolar.

Sobre as práticas epistêmicas, Kelly (2008 apud JIMÉNEZ-ALEIXANDRE E CRUJEIRAS, 2018) compreende que são um conjunto de ações padronizadas de um determinado grupo, tendo propósitos, expectativas, valores, ferramentas e significados culturais em comum. Desse modo, as práticas epistêmicas são delineadas como o jeito específico como uma comunidade propõe suas ideias, justificam-nas, avaliam e legitimam. Na educação científica, esse conjunto de ações está colocado para levar os estudantes a compreender a produção de conhecimento que se tem na comunidade de praticantes da ciência.

Jiménez-Aleixandre e Crujeiras (2018) apontam que existe uma sobreposição entre práticas científicas e práticas epistêmicas, mas recomendam a distinção delas para fim de pesquisa analítica. Nessa perspectiva, entendem as práticas epistêmicas como uma composição mais ampla do conhecimento e as práticas científicas como práticas 
Edição Especial: I SSAPEC - Simpósio Sul-Americano de Pesquisa em Ensino de Ciências

ISSN: 2595- $4520 \quad$ Vol. 4, n. 3. 2021

epistêmicas em um determinado contexto, considerando que essa sobreposição tem um limite, porque existem práticas somente científicas.

Consideramos importante a observação do desenvolvimento de práticas científicas e epistêmicas em concomitância, em situações de aprendizagem na educação básica, também por permitir visualizar e propor situações de ensino que se distinguem do mecanicismo e da transmissão de conteúdo, ainda muito presentes nesse nível da educação nacional, marcados pela passividade dos estudantes em atividades de verificação e exercícios de fixação.

Apesar de não haver um consenso sobre as práticas que são especificamente da comunidade científica, algumas autoras e autores têm feito importantes esforços em delineá-las, uma vez que essas práticas compõem a educação científica. Sem receios de assumir a temporalidade do conhecimento produzido nessa área, apresentamos uma categorização de práticas científicas e epistêmicas, proposta por Sasseron (2018), que nos auxiliaram nas análises. As práticas científicas serão enumeradas a seguir e identificadas pelas iniciais "PC". São elas: o trabalho com novas informações (PC1); o levantamento e o teste de hipóteses (PC2); a construção de explicações e a elaboração de justificativas, limites e previsões das explicações (PC3). As práticas epistêmicas, indicadas também pela autora, serão enumeradas a seguir. Essas identificam-se pelas iniciais "PE": proposição de ideias (PE1); comunicação de ideias (PE2); avaliação de ideias (PE3); legitimação de ideias (PE4).

Neste seguimento, entendendo a importância que a BNCC assume no cenário educacional brasileiro e que pesquisadores/pesquisadoras e profissionais do ensino de ciências têm defendido a alfabetização científica como fazer próprio de uma educação científica comprometida com a mudança social e, ainda, reconhecendo a importância que configura o desenvolvimento de práticas científicas e epistêmicas para a efetivação desse compromisso, assumimos, como objeto de investigação, as práticas científicas e as práticas epistêmicas presentes nas habilidades para o ensino de Ciências da BNCC para os anos finais do ensino fundamental. Dessa maneira, o objetivo deste trabalho é identificá-las e analisá-las, comparando-as às constatações feitas por Sasseron (2018) a partir da análise das habilidades propostas pela BNCC para os anos iniciais, a fim de contribuir para a pesquisa e para a prática no ensino de Ciências.

\section{METODOLOGIA}


Edição Especial: I SSAPEC - Simpósio Sul-Americano de Pesquisa em Ensino de Ciências

Para identificar as práticas científicas e epistêmicas nas habilidades do conhecimento da BNCC para a área de Ciências da Natureza dos anos finais do ensino fundamental, apoiamo-nos no trabalho realizado por Lúcia Helena Sasseron (2018), no qual a autora identificou as mesmas práticas na BNCC dos anos iniciais, e produzimos um percurso metodológico próprio.

Inicialmente, fizemos a relação entre prática e verbo de ação, considerando que uma prática é uma ação. Posteriormente, analisamos a identificação da autora para os anos iniciais do ensino fundamental com as seguintes etapas: identificação dos verbos de ação em cada habilidade; identificação de correspondência única entre verbo de ação e prática; aplicação dessa identificação às outras habilidades com o mesmo verbo de ação; eliminação dos verbos de ação e sua correspondência com práticas para encontrar novas correspondências diretas entre verbo de ação e prática até que esse procedimento não fosse mais possível; identificação por correspondência de palavras sinônimas. Ao final desse processo, percebemos que ainda havia práticas sem correspondência com verbos de ação, bem como não havia verbos de ação para identificar. Assim, assumimos duas possibilidades. A primeira foi a possibilidade de mais de um verbo corresponder a uma prática e a segunda foi a possibilidade de que outros tipos de palavras conotam a ação ou uma prática. A primeira possibilidade não se sustentou ao ser utilizada para mais de uma correspondência, sendo, por isso, descartada. A segunda possibilidade se mostrou mais consistente ao ser aplicada para correspondência em outras habilidades. Dessa forma, pôde-se constituir um banco de verbos de ação e palavras-chave que correspondem, cada qual, a uma prática científica ou epistêmica.

Após a composição desse banco de verbos de ação e palavras-chave, seguimos para a identificação das práticas científicas e epistêmicas nas habilidades dos objetos do conhecimento dos anos finais do ensino fundamental. A correspondência dos verbos de ação e palavras-chave com as habilidades mostrou uma eficiência de 68,6\%. Dos 137 verbos de ação e palavras-chave identificados nas habilidades do $6^{\circ}$ ao $9^{\circ}$ ano, 94 corresponderam àqueles reunidos a partir do trabalho de Sasseron (2018) e foram utilizados para identificar as práticas científicas e práticas epistêmicas nesse nível de ensino. Como pode-se deduzir, 31,4\% dos verbos de ação e palavras-chave identificados nas habilidades do $6^{\circ}$ ao $9^{\circ}$ ano ficaram sem correspondência com práticas científicas ou práticas epistêmicas. Sendo assim, a correspondência foi feita pelas autoras desta 
pesquisa, complementando-se os dados. $\mathrm{O}$ banco de verbos de ação e palavras-chaves utilizado para identificação das práticas é apresentado abaixo:

Quadro 2 - Banco de verbos de ação e palavras-chave utilizado para identificar as práticas científicas e epistêmicas nas habilidades da BNCC dos anos finais do ensino fundamental da área de Ciências da Natureza.

\begin{tabular}{|c|c|}
\hline Prática & Verbos de ação e palavras-chave \\
\hline $\mathrm{PC} 1$ & $\begin{array}{l}\text { Comparar; Reconhecer; Selecionar; Identificar; Identificar reconhecendo (+PC3); Concluir } \\
\text { (+PC3); Verificar; Associar (+PC3); Explorar; Investigar (+PC2, PC3, PE3); Considerar; } \\
\text { Destacar; Localizar; Observar; Experimentar; Testar; A partir; Com base; Classificar; } \\
\text { Diferenciar; Utilizar o conhecimento; Baseado. }\end{array}$ \\
\hline $\mathrm{PC} 2$ & Investigar (+PC1, PC3, PE3); Planejar e executar experimentos. \\
\hline PC3 & $\begin{array}{l}\text { Concluir (+PC1); Relacionar; Associar (+PC1); Justificar; Investigar (+PC1, PC2, PE3); } \\
\text { Explicar; Deduzir; Evidência; Demonstrar; Inferir; Caracterizar; Correlacionar; } \\
\text { Estabelecendo; Interpretar. }\end{array}$ \\
\hline PE1 & Construir proposta; Criar soluções; Propor; Projetar e construir; Organizar cardápio. \\
\hline PE2 & Discutir; Nomear; Descrever; Representar; Relatar; Comunicar; Simular. \\
\hline PE3 & $\begin{array}{l}\text { Investigar (+PC1,PC2,PE3); Analisar e construir; Produzir; Argumentos; Concluir com base } \\
\text { na observação e no registro; Aplicar; Analisar; Avaliando; Avaliar; Argumentar; Calcular; } \\
\text { Resolver problemas. }\end{array}$ \\
\hline PE4 & Construir soluções; Implementar proposta. \\
\hline & \\
\hline
\end{tabular}

por Sasseron (2018) para os anos inicias do ensino fundamental, a saber: (i) a quantidade de práticas científicas e epistêmicas e o comparativo entre elas; (ii) a quantidade de habilidades sem práticas científicas; (iii) a quantidade de habilidades sem práticas epistêmicas; (iv) a quantidade de habilidades com práticas científicas e epistêmicas ocorrendo em concomitância; (v) a frequência de cada prática.

Para auxiliar na comparação entre as práticas científicas e epistêmicas identificadas por Sasseron nas habilidades propostas para os anos iniciais e aquelas identificadas nesta pesquisa, buscamos os dados correspondentes no artigo de referência (Sasseron, 2018). Com base nesses dados, elaboramos uma tabela de frequência (tabela $2)$, de modo a reuni-los por segmento - anos iniciais ( $1^{\circ}$ ao $5^{\circ}$ ano $)$ e anos finais $\left(6^{\circ}\right.$ ao $9^{\circ}$ ano). A partir desse apanhado e das constatações apresentadas pela autora, tecemos nossas considerações.

\section{AS PRÁTICAS CIENTÍFICAS E EPISTÊMICAS NA BNCC PARA}

\section{O ENSINO DE CIÊNCIAS}

Recebido em: 18/01/2021

Aceito em: 24/02/2021 
O resultado da identificação de práticas epistêmicas e científicas das habilidades dos objetos de conhecimento de Ciências da Natureza da BNCC para os anos finais do ensino fundamental está sintetizado no Quadro 3. Cabe ressaltar que utilizamos os mesmos códigos da BNCC para identificar as habilidades.

Quadro 3 - Identificação de práticas científicas e epistêmicas nas habilidades da área de Ciências da Natureza na BNCC referentes ao $6^{\circ}, 7^{\circ}, 8^{\circ}, 9^{\circ}$ ano do ensino fundamental.

\begin{tabular}{|c|c|c|c|c|c|}
\hline $\begin{array}{l}\text { Habilidades } \\
\text { do } 6^{\circ} \text { ano }\end{array}$ & $\begin{array}{l}\text { Práticas } \\
\text { científicas }\end{array}$ & $\begin{array}{c}\text { Práticas } \\
\text { epistêmicas }\end{array}$ & $\begin{array}{c}\text { Habilidades do } \\
7^{\circ} \text { ano }\end{array}$ & $\begin{array}{l}\text { Práticas } \\
\text { científicas }\end{array}$ & $\begin{array}{c}\text { Práticas } \\
\text { epistêmicas }\end{array}$ \\
\hline (EF06CI01) & PC1 & ----------------- & (EF07CI01) & PC1 & PE1 PE2 \\
\hline (EF06CI02) & PC1 & ------------- & (EF07CI02) & PC1 & -------------- \\
\hline (EF06CI03) & PC1 & ----------------- & (EF07CI03) & PC1 PC3 & PE4 \\
\hline (EF06CI04) & PC1 $\mathrm{PC} 3$ & PE3 & (EF07CI04) & |--------------- & PE3 \\
\hline (EF06CI05) & PC3 & -------------- & (EF07CI05) & ------------- & PE2 PE3 \\
\hline (EF06CI06) & PC1 $\mathrm{PC} 3$ & ----------------- & (EF07CI06) & ----------------- & PE2 PE3 \\
\hline (EF06CI07) & PC1 $\quad$ PC3 & PE3 & (EF07CI07) & PC3 & ---------------- \\
\hline (EF06CI08) & $\mathrm{PC} 1 \quad \mathrm{PC} 3$ & ---------------- & (EF07CI08) & ----------------- & PE3 \\
\hline (EF06CI09) & PC3 & ---------------- & (EF07CI09) & PC1 PC3 & PE3 \\
\hline (EF06CI10) & PC3 & |---------------- & (EF07CI10) & PC1 & PE3 \\
\hline (EF06CI11) & PC1 & ----------------- & (EF07CI11) & PC1 & PE3 \\
\hline (EF06CI12) & $\begin{array}{ll}\text { PC1 } & \text { PC3 } \\
\end{array}$ & ----------------- & (EF07CI12) & $\begin{array}{ll}\mathrm{PC} 1 & \mathrm{PC} 3 \\
\end{array}$ & PE2 \\
\hline (EF06CI13) & $\begin{array}{ll}\text { PC1 } & \text { PC3 } \\
\end{array}$ & PE3 & (EF07CI13) & PC1 & PE2 PE4 \\
\hline (EF06CI14) & PC3 & --------------- & (EF07CI14) & PC1 $\mathrm{PC} 3$ & PE1 PE2 \\
\hline --------------- & ---------------- & ---------------- & (EF07CI15) & PC3 & ---------------- \\
\hline ----------------- & |---------------- & |---------------- & (EF07CI16) & PC1 $\mathrm{PC} 3$ & ---------------- \\
\hline $\begin{array}{c}\text { Habilidades } \\
\text { do } 8^{\circ} \text { ano }\end{array}$ & $\begin{array}{l}\text { Práticas } \\
\text { científicas }\end{array}$ & $\begin{array}{c}\text { Práticas } \\
\text { epistêmicas }\end{array}$ & $\begin{array}{l}\text { Habilidades do } \\
9^{\circ} \text { ano }\end{array}$ & $\begin{array}{l}\text { Práticas } \\
\text { científicas }\end{array}$ & $\begin{array}{c}\text { Práticas } \\
\text { epistêmicas }\end{array}$ \\
\hline (EF08CI01) & $\mathrm{PC} 1$ & ------------------ & (EF09CI01) & PC1 $\mathrm{PC} 3$ & PE3 \\
\hline (EF08CI02) & $\mathrm{PC} 1 \cap 2$ & PE4 $\odot$ & (EF09CI02) & PC1 $\mathrm{PC} 3$ & ----------------- \\
\hline (EF08CI03) & $\mathrm{PC} 1$ & ----------------- & (EF09CI03) & PC1 & ---------------- \\
\hline (EF08CI04) & PC1 & PE3 & (EF09CI04) & PC2 $\mathrm{PC} 3$ & --------------- \\
\hline (EF08CI05) & PC1 & PE1 & (EF09CI05) & PC2 & ----------------- \\
\hline (EF08CI06) & ----------------- & PE2 $\quad$ PE3 & (EF09CI06) & PC1 & PE2 PE3 \\
\hline (EF08CI07) & PC1 & ----------------- & (EF09CI07) & ----------------- & PE2 \\
\hline (EF08CI08) & PC1 $\mathrm{PC} 3$ & PE3 & (EF09CI08) & PC3 & ----------------- \\
\hline (EF08CI09) & PC1 $\mathrm{PC} 3$ & ----------------- & (EF09CI09) & PC1 & $\begin{array}{ll}\text { PE2 } & \text { PE3 } \\
\end{array}$ \\
\hline (EF08CI10) & PC1 & PE2 & (EF09CI10) & PC1 $\mathrm{PC} 3$ & ---------------- \\
\hline (EF08CI11) & PC1 & PE3 & (EF09CI11) & PC1 & PE2 \\
\hline (EF08CI12) & PC1 PC3 & PE1 & (EF09CI12) & PC1 $\mathrm{PC} 3$ & ---------------- \\
\hline (EF08CI13) & ---------------- & PE1 PE2 PE3 & (EF09CI13) & PC1 & PE1 \\
\hline (EF08CI14) & PC3 & |--------------- & (EF09CI14) & ----------------- & PE2 \\
\hline (EF08CI15) & PC1 & PE2 & (EF09CI15 & PC3 & ----------------- \\
\hline (EF08CI16) & PC1 & PE2 & (EF09CI16) & $\mathrm{PC} 1$ & PE3 \\
\hline ---------------- & ---------------- & ---------------- & (EF09CI17) & PC1 & PE3 \\
\hline
\end{tabular}

Fonte: Elaborado pelas autoras.

A partir dos dados apresentados, constatamos 119 práticas científicas e práticas epistêmicas associadas a habilidades dos objetos do conhecimento da área de Ciências 
da Natureza da BNCC para os anos finais do ensino fundamental, sendo 45 delas práticas epistêmicas e 74 práticas científicas.

Das 63 habilidades analisadas, 28 não apresentam práticas epistêmicas e 09 não apresentam práticas científicas, ou seja, 36 habilidades não apresentam práticas epistêmicas e científicas ocorrendo em concomitância, dado que essa concomitância ocorre em: 03 das 14 habilidades apresentadas para o $6^{\circ}$ ano; 08 das 16 habilidades apresentadas para o $7^{\circ}$ ano; 09 das 16 habilidades apresentadas para o $8^{\circ}$ ano; e, das 17 habilidades da BNCC para o $9^{\circ}$ ano, 07 possuem práticas científicas e epistêmicas ocorrendo ao mesmo tempo.

A ocorrência de cada prática em cada ano está identificada na tabela 1:

Tabela 1 - Quantidade de práticas científicas e epistêmicas em cada ano dos anos finais do ensino fundamental.

\begin{tabular}{c|c|c|c|c|c|c|c}
\hline Ano & PC1 & PC2 & PC3 & PE1 & PE2 & PE3 & PE4 \\
\hline $6^{\circ}$ ANO & 10 & - & 10 & - & - & 03 & - \\
\hline $7^{\circ}$ ANO & 10 & - & 07 & 02 & 07 & 07 & 01 \\
\hline $8^{\circ}$ ANO & 13 & - & 04 & 03 & 05 & 05 & 01 \\
\hline $9^{\circ}$ ANO & 11 & 02 & 07 & 01 & 05 & 05 & - \\
\hline TOTAL & 44 & 02 & 28 & 06 & 17 & 20 & 02 \\
\hline
\end{tabular}

A partir dos dados expostos, constatamos a predominância das práticas PC1 e PC3, que correspondem ao trabalho com novas informações e a construção de explicações, respectivamente, e quase ausência de PC2 (levantamento de hipóteses) e PE4 (legitimação de ideias).

Assim como Sasseron (2018), alertamos para o fato de que a análise aqui apresentada não corresponde diretamente ao ensino, pois este é planejado e executado por professoras/professores cuja autonomia para organização do próprio trabalho pode resultar em estratégias que modifiquem o cenário do qual partimos, ou seja, apenas um conjunto de habilidades propostas. Dito isso, os dados nos levam a inferir que as/os estudantes do $6^{\circ}$ ano concentrarão sua aprendizagem em trabalhar com novas informações (PC1) e construir explicações, elaborar justificativas, explicações e previsões a partir de suas explicações (PC3), e menos em avaliar ideias (PE3). Os dados também indicam que esses mesmos estudantes não terão oportunidade, de acordo com 
as habilidades propostas pelo documento, de desenvolver as demais práticas (PC2, PE1, PE2 e PE4).

Constatamos, também, que as/os estudantes do $7^{\circ}$ ano terão mais oportunidades de trabalhar com novas informações (PC1) e, mais raramente, de propor ideias (PE1) e legitimá-las (PE4). Já as/os estudantes do $8^{\circ}$ ano concentrarão sua aprendizagem em trabalhar com novas informações (PC1), destacando-se em maior quantidade dentre os anos finais do ensino fundamental, tendo menos oportunidades do que o $7^{\circ}$ ano em três das outras cinco práticas (PC3, PE2 e PE3). Enquanto isso, as/os estudantes do $9^{\circ}$ ano continuarão, assim como os demais, imprimindo maiores esforços em trabalhar com novas informações (PC1), bem como serão as/os únicas/únicos, dos anos finais do ensino fundamental, a ter a oportunidade de levantar e testar hipóteses (PC2), ainda que de forma modesta, com apenas uma correspondência com a proposição de ideias (PE1), mas nenhuma oportunidade de legitimá-las (PE4).

Passemos agora a comparar nossos dados às constatações feitas por Sasseron (2018) para os anos iniciais do ensino fundamental sobre a presença de práticas científicas e epistêmicas nos objetos do conhecimento da área de Ciências da Natureza, presentes na BNCC, para os anos iniciais.

A partir da análise apresentada pela autora, constata-se: (1) maior frequência de práticas científicas do que de práticas epistêmicas; (2) um número elevado de habilidades sem associação com práticas epistêmicas e um número menor de habilidades sem associação com práticas científicas; (3) alta incidência de habilidades que não apresentam práticas epistêmicas e práticas científicas conjuntamente; (4) nenhuma associação a PE4 (legitimação de ideias); (5) alta incidência de PC1 (obtenção de novas informações); (6) baixa incidência de PE3 (avaliação de ideias) e de PE1 (proposição de ideias) e; (7) dentre as práticas epistêmicas, maior ocorrência de PE2 (comunicação de ideias).

Para auxiliar na comparação entre as conclusões de Sasseron (2018) e os resultados desta pesquisa, utilizamos a tabela de frequência (tabela 2), que reúne os dados por segmento:

Tabela 2 - Frequência absoluta de práticas científicas e epistêmicas na BNCC do $1^{\circ}$ ao $9^{\circ}$ ano do ensino fundamental. 


\begin{tabular}{c|c|c|c|c|c|c|c}
\hline $\begin{array}{c}\text { Práticas } \\
\text { científicas }\end{array}$ & Frequência & $\begin{array}{c}\text { Práticas } \\
\text { epistêmicas }\end{array}$ & Frequência & $\begin{array}{c}\text { Práticas } \\
\text { científicas }\end{array}$ & Frequência & $\begin{array}{c}\text { Práticas } \\
\text { epistêmicas }\end{array}$ & Frequência \\
\hline PC1 & 0,49 & PE1 & 0,07 & PC1 & 0,37 & PE1 & 0,05 \\
\hline PC2 & 0,01 & PE2 & 0,19 & PC2 & 0,02 & PE2 & 0,14 \\
\hline PC3 & 0,13 & PE3 & 0,10 & PC3 & 0,23 & PE3 & 0,17 \\
\hline--- & --- & PE4 & 0 & --- & --- & PE4 & 0,02 \\
\hline Total & 0,63 & Total & 0,36 & Total & 0,62 & Total & 0,38 \\
\hline
\end{tabular}

Fonte: Dados produzidos pelas autoras a partir de informações extraídas do trabalho de Sasseron (2018) - do $1^{\circ}$ ao $5^{\circ}$ ano e de dados desta pesquisa $-6^{\circ}$ ao $9^{\circ}$ ano.

A análise da frequência de práticas científicas e práticas epistêmicas nos permite afirmar que há mais aproximações do que distanciamentos entre os dois segmentos.

Assim como Sasseron, identificamos, nos anos finais, uma frequência bem maior de práticas científicas em relação às práticas epistêmicas (constatação 1) e, dentre todas as práticas, $\mathrm{PC1}$ (trabalho com novas informações) também apresenta maior incidência (constatação 5). A alta incidência de PC1 nos anos iniciais do ensino fundamental foi observada pela autora como uma preferência do documento curricular nacional em fomentar a apresentação de novas informações. Nossos dados corroboram essa afirmação, uma vez que essa preferência se mantém nos anos finais do ensino fundamental, apontando uma divergência entre as habilidades e os objetivos propostos para a área das ciências pela própria BNCC. Nesse sentido, nossos resultados reforçam a afirmação de Sasseron de que a presença majoritária dessa prática vai de encontro à proposta de um ensino-aprendizagem que permita aos estudantes terem contato com a atividade científica para além da abordagem meramente conceitual tradicionalmente presente em aulas de Ciências.

Também observamos para os anos finais, como na análise realizada nos anos iniciais, a baixa frequência de PE1 (proposição de ideias) e de PE4 (legitimação de ideias) (constatação 4), sendo esta ausente no segmento de $1^{\circ}$ ao $5^{\circ}$ ano. A baixa frequência de PE1 (parte da constatação 6), segundo Sasseron (2018, p. 1076):

[...] não favorece a promoção de situações em que os estudantes possam se envolver com atividades que gerem a proposição de ideias, medidas ou de artefatos, produtos do trabalho intelectual que pode ser realizado em sala de aula.

A presença quase imperceptível de PE4, que se aproxima da ausência detectada nos anos iniciais, leva-nos a concordar com a autora, que afirma parecer pouco coerente com o anúncio de complexificação das temáticas (Matéria e Energia, Vida e Evolução, 
Terra e Universo) abordadas pelo documento em toda a área de Ciências da Natureza, uma vez que práticas de legitimação devem fazer parte da retomada de compreensões já construídas em processos contínuos de construção de conhecimentos. Além disso, procedimentos e atitudes de legitimação, apontados por Silva e colaboradores (2017), tais como construção de consensos sobre explicações científicas e reconhecimento da relevância de conhecimentos científicos para a comunidade epistêmica, são importantes para a compreensão da ciência e inserção dos estudantes nessa cultura.

Além da comparação possível pela análise dos dados da tabela 2, as constatações 2 e 3 da autora também foram observadas na análise que fizemos para os anos finais do ensino fundamental a partir dos demais dados produzidos. Assim, temos um elevado número de habilidades sem associação a práticas epistêmicas, sendo 20 habilidades sem essa associação nos anos iniciais do ensino fundamental, ou seja, quase $42 \%$ das habilidades não apresentam práticas epistêmicas, comparáveis aos $44 \%$ nos anos finais. Ainda, constatamos que 36 das 63 habilidades dos anos finais do ensino fundamental não apresentam práticas científicas e epistêmicas ocorrendo na mesma habilidade. Para os anos iniciais, têm-se 25 habilidades sem associação entre as duas práticas em concomitância. Desse modo, apontamos que 61 das 111 habilidades dos objetos do conhecimento para a área das Ciências da Natureza no ensino fundamental não apresentam associação entre práticas científicas e práticas epistêmicas em concomitância, ou seja, quase $60 \%$ das habilidades não promovem o processo de compreensão da construção do conhecimento epistêmico da ciência enquanto promovem o processo de construção da prática de cientistas.

Esses foram os pontos de maior convergência com as constatações feitas por Sasseron, indicando a manutenção de algumas incoerências e contradições destacadas pela autora.

Além da comparação com as constatações feitas por Sasseron, reunindo os dados das duas pesquisas, podemos afirmar que há baixa frequência de PC2 (o levantamento e teste de hipóteses) em todo o ensino fundamental, o que indica pouca relevância dada aos conhecimentos prévios dos estudantes, sendo este aspecto fundamental em propostas que visem à aproximação com as práticas cotidianas dos alunos como forma de construção de novas ideias e conhecimentos sobre os fenômenos naturais. 
Ademais, pode-se observar uma diminuição de PC1 (o trabalho com novas informações), um aumento de PC3 (a construção de explicações) e um aumento de PE3 (a avaliação das ideias) dos anos iniciais para os anos finais.

Vale destacar que o aumento na frequência de PE3 (a avaliação das ideias) a configura como a prática epistêmica de maior ocorrência nos anos finais do ensino fundamental. Contudo, é importante termos cautela com esse dado, uma vez que existe uma disparidade entre a frequência dessa prática frente às práticas mais frequentes (PC1 e PC3). Essa ponderação também é necessária quando se tem em mente que "o processo de avaliação é central e crítico para o desenvolvimento das ciências [..]" (SASSERON, 2018, p. 1075), mas a baixíssima frequência de PC2 (o levantamento e o teste de hipóteses) e pouca presença de PE1 (a proposição das ideias), práticas que, em nosso entendimento, sustentam o desenvolvimento de PE3, leva-nos a questionar quais ideias serão avaliadas no processo de desenvolvimento dessa prática. Entendemos que as ideias que os estudantes propõem e testam sejam as mais adequadas para a promoção da alfabetização científica e, portanto, as mais adequadas para serem avaliadas durante o processo de aprendizagem.

Ainda precisamos nos dedicar à percepção da diminuição da frequência de PC1 (o trabalho com novas informações) nos anos finais do ensino fundamental. Apesar da diminuição, essa prática ainda figura como a mais frequente nos anos finais. No entanto, queremos acrescentar a percepção do aumento da prática PC3 (a construção de explicações), parecendo-nos correto apontar que a BNCC indica que o ensino fundamental deve concentrar a aprendizagem em desenvolver PC1 e PC3, já que essas configuram-se as práticas mais frequentes em todo o ensino fundamental, cerca de $60 \%$ de todas as práticas identificadas.

Considerando a BNCC um importante instrumento para a construção do ensino de Ciências em nosso país, uma vez que é um documento oficial, ao notarmos a maior incidência de habilidades dedicadas a práticas científicas já estabelecidas em sala de aula, não conseguimos apontá-la como um documento que avance efetivamente em propostas inovadoras para o ensino de Ciências, especialmente no que diz respeito à promoção da alfabetização científica nas escolas brasileiras.

\section{CONSIDERAÇÕES FINAIS}


Neste artigo, identificamos e analisamos as práticas científicas e epistêmicas associadas às habilidades propostas pela BNCC para os anos finais do ensino fundamental, na área de Ciências da Natureza. Utilizamos como referência o trabalho de Sasseron (2018), no qual essas práticas são identificadas e analisadas no conjunto de habilidades indicadas para os anos iniciais.

$\mathrm{Da}$ análise que fizemos para os anos finais, destacamos algumas constatações que se aproximam da pesquisa de Sasseron, tal como outras que foram observadas na comparação entre os dois segmentos de ensino.

Assim como Sasseron, pudemos observar um desequilíbrio entre práticas científicas e epistêmicas, bem como uma quantidade bem expressiva de habilidades que não as relacionam concomitantemente, o que, segundo Sasseron (2018), pode levar à ocorrência de práticas sem reflexão e de forma mecânica em aulas de Ciências no ensino fundamental.

A alta frequência de PC1 e PC3, em detrimento das demais práticas, a inexpressividade do levantamento e teste de hipóteses (PC2), assim como da legitimação das ideias (PE4), permite-nos apontar que a ação investigativa, para o ensino de Ciências, é pouco expressiva no documento. Desse modo, parece-nos incoerente que um documento que anuncie a alfabetização científica como objetivo da educação em ciências cujos objetivos relacionam-se à compreensão, pelas/pelos estudantes, do processo de construção e comunicação do conhecimento científico para que, a partir desse conhecimento, ampliem as possibilidades de interferir nesse mundo, dedique tanto espaço ao trabalho com novas informações (PC1), visto que isso indicaria a manutenção de um ensino tradicionalmente focado na apresentação de conceitos e de explicações pela/pelo professora/professor. Se adicionarmos o fato de a prática científica de construção de explicações e a elaboração de justificativas, limites e previsões das explicações (PC3) ser a segunda prática mais recorrente, perceberemos com mais clareza o favorecimento da manutenção desse tipo de ensino, no qual estudantes são bombardeados de informações em sala de aula, precisando de usá-las para explicar situações geralmente distintas da realidade na qual estão inseridos.

Entendemos que o exercício do processo de produção de conhecimento da ciência dá-se por meio de práticas e que não existe argumentação quanto a trabalhar mais com uma prática em detrimento das demais. É necessário que se dê atenção a todas elas, de forma equânime e conjunta. 
Esses pontos nos chamam a atenção para uma consideração importante: a BNCC é um direcionamento do trabalho docente, mas a concretização desse trabalho depende do planejamento e execução das/dos profissionais do ensino de Ciências. Destarte, as incoerências e contradições identificadas na BNCC para a área de Ciências da Natureza podem ser contornadas em sala de aula, considerando a autonomia das professoras e professores na elaboração de ações e estratégias de ensino e aprendizagem, mediante investimento na formação dessas/desses profissionais para o uso da investigação em aulas de Ciências, assim como nas pesquisas sobre o conhecimento construído por eles na prática profissional

\section{REFERÊNCIAS}

DUSCHL, R. A. (2008). Science education in three-part harmony: balancing conceptual, epistemic and social learning goals. In: Review of Research in Education, 32(1), p. 268-291.

JIMÉNEZ-ALEIXANDRE, M. P., \& CRUJEIRAS, B. (2018) Epistemic practices and scientific practices. In: science education. In Taber, K. S, \& Akpan, B. (Eds.). Science Education: an International Course Companion, p. 69-80

MACEDO, Elizabeth. Base Nacional Curricular Comum: novas formas de sociabilidade produzindo sentidos para a educação. In: Revista e-Curriculum. São Paulo, v. 12, n. 03 p.1530 - 1555 out./dez. $2014 . \quad$ Disponível https://revistas.pucsp.br/curriculum/article/view/21666. Acesso em: 10 jan. 2020.

MEC, Ministério da Educação (2017). Base Nacional Comum Curricular, Brasília: Secretaria Ins da http://download.basenacionalcomum.mec.gov.br/. Acesso em: 20 jan. 2020.

SASSERON, Lúcia Helena. Ensino de ciências por Investigação e o Desenvolvimento de Práticas: Uma Mirada para a Base Nacional Comum Curricular. In: Revista Brasileira de Pesquisa em Educação em Ciências. v. 18(3), p. 1061-1085, 2018.

SASSERON, Lúcia Helena; CARVALHO, Anna Maria Pessoa de. Alfabetização Científica: uma revisão bibliográfica. Investigações em Ensino de Ciências (Online), v. 16, p. 59-77, 2011. Disponível em: https://www.if.ufrgs.br/cref/ojs/index.php/ienci/article/view/246. Acesso em: 20 jan. 2020.

SILVA, M.B.; GEROLIN, E.C.; TRIVELATO, S.L.F. Práticas epistêmicas no ensino de Biologia: Constituição de uma comunidade de práticas em uma atividade investigativa. In: X Congresso Internacional sobre Investigación em Didáctica de lãs Ciencias. Sevilla, 5-8 de septiembre de 2017.

SILVA, R.S. A mediação pedagógica no desenvolvimento de uma sequência de ensino investigativa que articula conhecimentos astronômicos e físicos. Dissertação de Mestrado. Programa de Mestrado Profissional em Ensino de Física PPGEnFis/Ufes. Vitória. 144p. 2019. 